\title{
English in Bilingual Promotional Material of Chinese Maritime-related Exhibition Publicity: A discourse Analysis Study
}

\author{
Junjie Ma ${ }^{1 *}$, Yingxin $\mathrm{Ma}^{1}$ \\ ${ }^{1}$ The University of Edinburgh, United Kingdom, \\ ${ }^{1}$ Yingxin Ma, The University of Edinburgh, United Kingdom,
}

\begin{tabular}{|c|c|c|c|}
\hline Received: 30.11.2021 & - $\quad$ Accepted: 25.01.2021 & - Published: 28.02.2022 & - Final Version: 01.03.2022 \\
\hline
\end{tabular}

\begin{abstract}
In recent years, the numbers of bilingual advertising texts have increased in China's international maritime exhibitions. Nevertheless, the shortcomings in wording and phrasing, usage of translation strategies and intercultural communication in these China English texts are not only contrary to the Plain English Movement which advocated a more concise and economical use of words and sentences in the late 20th century, but also adversely affect the Belt and Road Initiative as well as intercultural communication. In this paper, various promotional material collected from major maritime-related English exhibitions in China over the past three years will be taken as examples. This paper will adopt the discourse analysis theory to summarize the problems of redundancy, Chinglish, misuse of translation strategies and mismanagement of intercultural conflict in relevant bilingual advertisements. The paper then suggests a series of ways for improvement in order to improve the quality of China English texts as well as promote intercultural communication.
\end{abstract}

Keywords: China English, Discourse analysis, Plain English, post-editing, Translation strategy

\section{Introduction}

The concepts of English as a lingua franca (ELF) and English as a world language (EWL) have risen from globalization trends, as defined by Giddens (1990). The required global communications have drawn 'great attention' to countries which use English as a foreign language in recent decades (Jenkins, 2014). From Hu's (2005) point of view, due to the inseparable relationship between English and globalization, this language is also called Global English, International English or World English. Against the background of globalization, Global English has become the lingua franca that allows people from all over the world to communicate with each other efficiently (McArthur, 2004). $\mathrm{Hu}$ (2005) further claims that the number of English learners has begun to rise in China because of the need for building bridges between China and other countries. This has further led to the continuous improvement of Chinese citizens' English level and the growing popularity of English in business communication. In this context, the application of Global English in China has led to the gradual formation of a new variety of English, namely China English.

The 'China English' concept has been discussed for two decades. According to Du and Jiang (2001), China English refers to the English that is used by Chinese people, mixing standard English with

\footnotetext{
*Junjie Ma: s2168595@ed.ac.uk
} 
Chinese language features. Both Li (1993) and Butler (1997) propose that China English has included typical Chinese characteristics in terms of discourse, lexis and sentence structure, but does not demonstrate any L1 (first language) interference. Accordingly, China English can be regarded as a 'native variety of English' because of its recognizable long-inherited pronunciation as well as its 'peculiar vocabulary and phrase expression' (Kirkpatrick \& Xu, 2002).

As one of the major varieties of English in the world, the development of China English has also inevitably brought about some significant problems. Both Pinkham (2000) and Li (2012) point out the shortcomings of China English in terms of language expression, style and rhetoric. Such 'English with Chinese characteristics' is widely found in street advertisements and in English translations of Chinese business reports (Pinkham, 2000), and is also well represented in the data collected by the authors. Some researchers have raised and analyzed the problems of Chinese English texts (Li, 2012; Pinkham, 2000). However, there is a lack of focused discussion and systematic categorization regarding these typical shortcomings of China English in business exhibitions. Both Bi (2009) and Lian (2010) emphasize the importance of China English in the intercultural communication field and suggest relevant improvements. Nevertheless, shortcomings concerning translation strategies have not been the focus of the study. Liang and Guo (2020) have analyzed the translation problems in promotional materials for specific Chinese maritime-related exhibitions. Liang and Ma (2020) further adopt discourse analysis to discuss the redundancy of publicity about the Chinese maritimerelated exhibitions. This inspired us to group together several English texts from maritime-related exhibitions conducted in recent years, in order to categorize the types of shortcomings prevalent within them.

The Belt and Road Initiative, as well as increasing intercultural communication, contributed to the use of China English in business documents. According to Liang and Guo (2020), Chinese enterprises and organizations with English names and advertising slogans accounted for $41.75 \%$ (612), 49.57\% (692) and 88.46\% (368) of the participants at the China Marine Economy Expo in 2018, 2019 and 2020, respectively. Owing to the differences between Chinese and English expression conventions and the translation deficiencies, the English part of the advertising texts may exhibit a series of problems. Consequently, such issues will have a negative effect on various aspects of intercultural communication.

This paper discusses the redundancy of statements, misuse of translation strategies and Chinglish expressions in various bilingual promotions of previous Chinese maritime-related exhibitions. Suggestions are put forward as to how to correct these problems. The paper aims to summarize the main problems with China English texts from Chinese major maritime-related exhibitions, and to consider translation theories as well as intercultural competency in order to solve these problems. In doing so, we endeavor to contribute to the promotion of effective cultural exchanges between China and the rest of the world.

\section{Theoretical Foundations}

\section{The Discourse Analysis Approach}

According to Mills (1997), discourse analysis is a research method that studies the relationship between written or spoken language and its social context. It aims to understand how language is used in real life. Gee (2014) further summarizes that discourse analysis emphasizes the contextual meaning of language, rather than focusing only on the rules of language use. Its focus includes cultural rules and conventions in communication, as well as the purpose and expressive effects of different types of language. As a result, discourse analysis is widely cited as a qualitative research method in linguistics, education, and other fields. The levels of communication included in discourse analysis are listed in Table 1. 


\begin{tabular}{ll}
\hline \multicolumn{1}{c}{ Level of Communication } & \multicolumn{1}{c}{ Content of Analysis } \\
\hline Vocabulary & $\begin{array}{l}\text { Words and phrases can be analyzed for ideological associations, } \\
\text { forms, euphemisms and metaphorical content. }\end{array}$ \\
Trammar & The way sentences are constructed (e.g., verb tenses, active or \\
& passive constructions, and the use of imperatives and \\
& interrogatives) can reveal aspects of intended meaning. \\
Structure & The structure of the text can be analyzed to see how it creates \\
& focus or builds the narrative. \\
Genre & $\begin{array}{l}\text { Texts can be analyzed according to the conventions of their genre } \\
\text { (e.g., government documents or tabloid articles) and their } \\
\text { communicative purpose. }\end{array}$ \\
\hline
\end{tabular}

Table 1. Levels of communication included in discourse analysis (Jorgensen \& Phillips, 2011).

It is clear that the discourse analysis theory is well suited to the analysis of the wording of texts and the meanings they convey. In recent years, some scholars have made use of discourse analysis to explore the power relations and purposes embedded in policy texts and translated texts (Anderson \& Holloway, 2018; Liang \& Guo, 2020; Song, 2019). Nevertheless, studies on the discourse analysis of Chinese maritime-related exhibition texts have gone unnoticed. Besides, the discourse analysis does not focus on the shortcomings and corrections of these texts. In addition to the discourse analysis, the texts need lexical, grammatical and target audience analyses, so as to consider whether translation and writing theories have been correctly applied to these texts. In this research, relevant analyses theories are combined to support our arguments about the shortcomings of the aforementioned English promotional texts and provide suggestions on how to correct them. This study focuses on addressing the shortcomings of China English, so as to improve the effectiveness and efficiency of communication and achieve the ultimate goal of intercultural communication.

\section{Research Methodology}

\subsection{Research Methods}

So far there is no official policy to regulate the translation of texts at Chinese maritime-related exhibitions. Therefore, it is necessary to collect and analyze data to address the above questions. This paper adopts qualitative research methods to collect 208 advertising texts for Chinese maritimerelated exhibitions from 2018 to 2020, and analyzes the typical deficiencies in these texts, including redundancy, Chinglish expressions, abuse of CAT technology and Chinese pinyin. These research methods have been proven to ensure the objectivity of the results.

Discourse analysis is used to analyze the collected data, starting from August 2020. The reason for adopting such a research method was the availability of relatively abundant corresponding data from which the authors could adequately select typical case texts for analysis, including their shortcomings and corrections. Furthermore, discourse analysis based on these cases can be effectively combined with relevant translation theories to better analyze the lexical and grammatical shortcomings of these publicity materials.

The data (208 promotional texts) were collected from three Chinese maritime-related exhibitions from November 2018 to June 2020. The authors had worked as bilingual volunteers at China's principal maritime exhibitions, namely China Marine Economic Expo (CMEE) and China 
Aquaculture Products Expo (CAPE), since November 23, 2018. Thus, it was convenient to gather the relevant materials, like the official brochures of the exhibitions as well as the exhibitors' brochures. The authors also chose to collect the specific texts typically used to promote the exhibitions in recent years because of the negative public perception of the level of English language in these texts. The shortcomings of each representative data point are analyzed and corrected based on the theoretical principles.

\subsection{Research Questions}

This paper aims to reveal a series of problems with the English translations of promotional texts used for Chinese maritime exhibitions in recent years, and to provide suggestions on how to rectify them. This has positive implications for improving the overall standard of Chinese exhibition translation and the future development of China English. The research interrogates the following questions:

(1) What are the problems with these bilingual promotional texts?

(2) What are the implications of these problems for exhibitions and intercultural communication?

(3) What should be done to improve these problematic texts?

\section{Research Findings and Discussions}

\subsection{Findings}

The authors' analysis revealed five kinds of deficiencies in the examined bilingual texts redundant English, Chinglish expressions, the abuse of translation strategies, the abuse of CAT technology and the mishandling of intercultural conflict.

Of the 208 bilingual texts examined, 48 English translations (23\%) were cases of redundant English, while 27 Chinese translations (13\%) were cases of Chinglish expressions. A total of 37 English translations (18\%) were cases of the abuse of translation strategies, while 10 English translations (4.8\%) were cases of abuse of CAT technology. Finally, 23 English translations (11\%) were cases of mishandling of intercultural conflict. Table 2 depicts these findings.

\section{Type of Shortcoming}

Redundant English

Chinglish expressions

Abuse of translation strategies

Abuse of CAT technology

Mishandling of intercultural conflict
Number
$23 \%$

$18 \%$

$11 \%$
Proportion

\section{Table 2. The data from Chinese maritime-related exhibition publicity materials.}

\subsection{Redundant English}

First of all, the data above reveals that the cases of redundant English in promotional materials are the most frequent of all types of shortcomings. Li (2012) claims that the most significant problem of Chinese English texts is redundancy compared to the abuse of translation strategies, CAT technology, and intercultural communication conflicts. To analyze the problem of redundancy in texts, it is first necessary to clarify the definition of redundant English. the term 'Redundant English' refers to the style of writing in English as a native language text, such as government documents, business information, etc., that are designed to be stereotypical or to circumvent the law, and that 
may be confusing to the general public (Pinkham, 2000). Complex language structures and obscure words and phrases are often used in this genre (sometimes even in non-English texts).

Lian (2010) and Pinkham (2000) both propose that the redundant English has become a linguistic habit of Chinese people to explicitly specify the category of the discussed objects. However, such overspecification is seldomly used by native English speakers. In English, a word by itself may indicate its category without the need for an additional word, explicitly naming the category. This overspecification in English translations does not add any substance; rather it only makes sentences redundant. Thus, this problem should be noted and rectified (Gowers, 2014; Li, 2012). Here is an example of redundant promotional text, from publicity material used to promote CMEE (2018):

CMEE attracts exhibitors from countries along the $21^{\text {st }}$ Century Maritime Silk Road and from countries with advanced maritime economy.

In this sentence, 'countries' is used twice as a noun. According to the principle of Plain English given by Garbl's Plain Language Resources (2020), we can replace this noun with a pronoun, or rephrase using conjunctions. In this case, the phrase 'from countries' can be modified to 'those (from)'. Thus, the whole sentence can be rephrased as 'CMEE attracts exhibitors from advanced maritime economy countries, and those along the $21{ }^{\text {st }}$ Century Maritime Silk Road'. This rephrasing is concise, clear and more successful in conveying the intended meaning.

$\mathrm{Li} \mathrm{(2012)} \mathrm{and} \mathrm{Xu}$ (2018) also pointed out that English sentences are different from Chinese sentences. In long Chinese sentences, it is common practice to use a comma as separation, which enables easy understanding (Lian, 2010). However, the misuse of commas in long English sentences results in a difficult to digest text. Such sentences contain too much information, and the misuse of commas does not make them easier to understand. The following promotional text, by the Guangdong Rainbow Aquatic Development Co., Ltd., constitutes an example of this specific problem:

Since the beginning, the factory has taken 'high-quality and safety take the quality first' as the guideline, organized production with high starting point, high standards and high requirements in order to achieve the first-class international level of products and provide $100 \%$ qualified and satisfactory products for customers.

This sentence contains a total of four pieces of information. These are, as follows: the guideline of the factory; the high standard of organizing production; products that meet a first-class international level; providing high quality products for customers. The sentence contains 48 words, which is too long. According to the Office of Investor Education and Assistance's (1998) proposal and Plain English principle, one sentence should be at most 15-20 words. Based on this, the sentence needs to be edited to read as follows:

The factory has set 'quality first' as its goal; organized production with high requirements from the outset. We want to provide $100 \%$ satisfactory products, achieving a first-class international level for customers.

This way, the original redundant sentence, with four pieces of information, is split into two short sentences containing only two pieces of information each. This is a concise and clear sentence that is far easier for the reader to understand.

\subsection{Chinglish Expression}

Li (2012) has defined the concept of 'Chinglish' as that 'misshapen, hybrid language which is neither English nor Chinese but might be described as 'English with Chinese characteristics' (Pinkham, 2000, p. 1). It is one of the most 'significant negative' features of China English, in which 
a literal translation of certain Chinese expressions is used; however, these expressions are difficult to understand, as they do not fit English expression conventions (Pinkham, 2000; Newmark, 2004). A typical example is the following, from CAPE (2019) exhibitors:

The company takes the road of 'Pragmatic and integrity, scientific management, positive innovation' to manage.

In this sentence, the phrase 'take the road of' is an expression in English that reflects the pragmatic thought of the Chinese language. In Chinese, people often use the metaphor zou... de dao lu 走... 道 路 (literally meaning 'take the road of...') to express the essence of something, or the spirit of something. However, this is not a metaphor used in native English. Thus, it causes foreign readers to be somewhat confused. In this sentence, the translator wants to stress the excellent ideas of management. Thus, the sentence can be edited to read as follows:

Our management motto is 'Pragmatism with integrity, scientific management and positive innovation'.

This way, the sentence is clear and natural in presenting the idea of strong management. It is also much easier for readers to understand.

\subsection{The Abuse of Translation Strategies}

As a classic translation technique fallacy, 'word-for-word translation' is one of the most common translation errors in the English translations of texts used in promotional documents for major Chinese maritime exhibitions in recent years (Liang \& Guo, 2020; Li \& Chen, 2014, Yao, 2015). Baker (2000) has given the definition of the concept 'word-for-word translation'; that is to maintain both the content and the form of the original text in a translation where the language conditions of the translation permit. There are situations where word-for-word translation is acceptable, due to commonalities between the Chinese and English languages, according to House (2008). However, the term 'word-for-word translation' is more often a far-fetched adherence to the theory of 'word for word equivalence'. The proponents of this translation technique actually misinterpret the 'very faithful' theory insisted on by the prestigious Chinese translator $\mathrm{Lu}$ Xun and others. The disadvantage of this kind of translation is that the form of the translation forcibly corresponds to the original language, which is not in line with the linguistic conventions of the target language. Also, the translations contain a great deal of 'new expressions' that do not exist in the target language and are difficult for the target language speakers to understand. This affects the quality of the translations and can even negatively impact the reputations of such exhibitions (Chen, 1999). Here is an example of an official flyer from CMEE (2018) affected by this problem:

\section{媒体合作 (Media Cooperation); 传播升级 (Spread Upgrade)}

In this case, the promotional material has mei ti媒体 ('media'), hezuo合作 ('cooperation'), chuanbo传播 ('spread') and shengji升级 ('upgrade'). Thus, this text uses word-for-word translation strategy to convey meaning. However, in this instance, the use of this strategy may cause some ambiguity. Since the English translation does not specify what is being 'spread', the readers are likely to be confused about this. The use of this word in English can refer to both good things and bad things, for instance 'spread of viruses'. As a result, this ambiguity may well result in a negative connotation for some foreign exhibitors. The Chinese characters in this flyer mean 'through the cooperation of the medias to promote the publicity more extensively'. Thus, the text can be amended to 'To cooperate with the media, for a larger information coverage'. This amended text can convey the idea unambiguously.

\subsection{The Abuse of CAT Technology}


Munday (2008) has defined the notion of CAT: CAT (Computer Assisted Translation) technology refers to the use of a machine (usually a computer) to translate utterances from one natural language to another. CAT is a product of the development of computer science. According to Craciunescu et al. (2004), the use of CAT can help avoid the cost of hiring a large number of translators. Relevant statistics show that a translator can only translate 4-6 pages, or 2,000 words per day, for a difficult discourse. Although CAT is convenient for all types of text, O'Hagan (2020) argues that the core of CAT is still the translator. If Chinese translators adopt the output of a CAT without reviewing it, there is a high risk of grammatical and even content problems in the translated texts.

Yao (2015) claims that at present, Chinese maritime exhibitions are widely assisted by computer software applications for signage translation and indicator translation. However, if the translators rely too heavily on the CAT technology and adopt its output outright without reviewing the text, they are likely to produce irrelevant and misleading text (Hu, 2019; Xu, 2018). Figure 1 illustrates a typical example of this abuse of the CAT technology, taken by Liang and Guo in CAPE (2020):

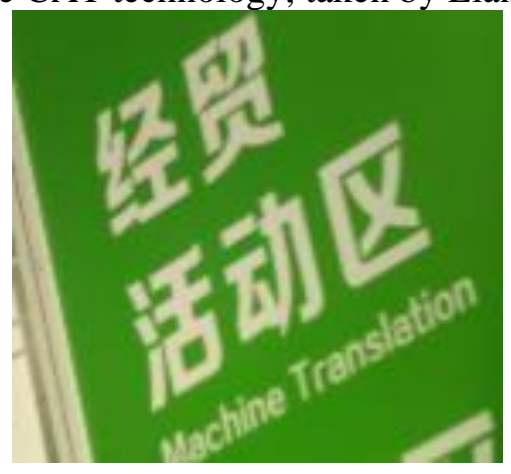

Figure 1. The output of CAT in China Aquaculture Products Expo. (By Liang \& Guo, 2020)

In this signage, the Chinese characters jing mao huo dong qu 经贸活动区signify 'Economic and Trade Activity Zone'. However, the text has been translated directly as 'Machine Translation' on a sign that is placed prominently at the main entrance of the exhibition. This will undoubtedly bring great inconvenience to the businessmen and guests who attend the exhibition, and may have a serious impact on the exhibition itself and even the image of the city in the visitors' minds. To rectify such errors, the translators and editors assisting the exhibition should double-check the output texts of the CAT and carefully revise any inappropriate parts of the texts.

\subsection{The Mismanagement of Intercultural Conflict}

Due to the existence of language and cultural differences, cultural misinterpretation is often inevitable when different cultural groups engage in intercultural communication (Halliday et al., 2004; Hu, 2019). Liang and Guo (2020) further claim that as the main manifestation of intercultural communication conflicts, cultural misinterpretation appears because the source language translators are not familiar with the culture of the target language. They tend to choose the wrong alternative vocabulary in some contexts. The following example concerns the entrepreneurial spirit of a fishery company from CMEE (2019):

ke hu wei tian客户为天 ('Customer is god')

The translator tries to emphasize the exalted status of the consumer by replacing the supreme 'heaven' of Eastern philosophy with the 'god' of Western religious beliefs. However, the translator has misunderstood the cultural context. According to Bi (2009, p. 98), 'Customer is God' came from the Japanese singer Minami Haruo’s lyrics ‘お客様は神様です’ (literally meaning ‘The customer is a god') instead of a Western proverb. Westerners do not use the term 'god' to describe customers. More importantly, the use of taboo terms like 'God' may be offensive to Westerners (Allan \& 
Burridge, 2009). This would undoubtedly have a negative impact on any international affairs interaction. Nevertheless, the expression 'The customer is king' is frequently used in English (Bi, 2009). Thus, we can replace the expression with either 'The customer is king' or 'The customer is always right', which are more idiomatic.

Moreover, the Economic and Trade Activity Zone of CMEE (2018) is signposted to remind exhibitors and visitors not to smoke in this area, with the following wording:

qing bu yao zai ci xi yan 请不要在此吸烟 ('No smoking here. Please')

In this case, the translators attempt to achieve the goal of reminding guests not to smoke in this area. Nevertheless, Bao (1999) asserts that in English expressions, the addition of the '-ing' form of the verb after 'No' takes on a strong imperative tone. Meanwhile, adding 'please' after this sentence is inappropriate and creates ambiguity for native English speakers. Under this circumstance, translators can avoid potential intercultural conflicts by deleting 'please' or rewriting the English text as 'Please don't smoke here!'.

\section{Recommendation}

We suggest that qualitative research methods such as discourse analysis should be adopted in more future Chinese maritime-related exhibitions to classify and analyze the grammatical and content errors as well as linguistic features of China English promotional materials. Johnstone (2011) also argues that discourse analysis theory is particularly suitable for case study research in translation and sociolinguistics. By conducting qualitative research, translators can see more clearly the typical problems of the text. At the same time, the corresponding corrections need to be factored in. This is because it can help translators to summarize representative problems and thus improve the accuracy of China English.

\section{Limitation of the Research}

First and foremost, this research focuses on three Chinese maritime-related exhibitions. However, the three Chinese maritime-related exhibitions do not represent the overall situation of English texts of Chinese maritime-related exhibitions. In a like manner, although this research summarizes the five aspects of Chinese English promotional texts in a more comprehensive way, the number of representative cases is not sufficient, which may adversely affect the persuasiveness of the language data.

During the data collection process, the authors also inevitably received the effects of the Covid19 , which resulted in many representative paper-based promotional materials not being collected and not being preserved. In the future, the author will try to adopt online data collection and screenshots to ensure the permanence and validity of the language data.

\section{Further Suggestions for the Improvement of Chinese Maritime Promotional Materials}

In view of the above-mentioned typical shortcomings in Chinese maritime-related exhibition promotional texts, the following suggestions to improve such China English texts may be followed.

First and foremost, the level of the maritime-related exhibitions' translators needs to be improved. The Chinese translators and language learners should strengthen their study of English-Chinese translation comparison theories and develop a grasp of the current development trends of the English language, thereby improving their translation skills (Liang \& Guo, 2020; Sun, 2016). English language developments such as the Plain English movement need to be paid more attention by Chinese translators in order to avoid writing redundant and complex English texts. Not only that, the 
exhibition organizers could also increase their selection efforts and hire professional translators for any translation tasks wherever possible.

Secondly, translators should not blindly trust the output of CAT software application. According to Lian (2010) and Yao (2015), the central role in translation is still that of the translator themselves. The translator should be very careful with these types of translated texts. This is not only restricted to carefully checking the content, but also by reviewing the English translation for common expressions such as the indicated tense and any personal pronouns. The translated English texts should be used only after they have been reviewed for accuracy.

Thirdly, Chinese translators and language learners should strengthen their intercultural competence. Intercultural communication is an important assurance for the success of global language and cultural exchange (Halliday et al., 2004). The Chinese translators and language learners should be more familiar with the culture of the target language, and fully understand, as well as indulge, other cultures. Only in this way can English translations of China texts successfully facilitate intercultural communication in any maritime exhibitions and promote the 'Belt and Road Initiative' advocated by China.

\section{Concluding Remarks}

The English translations of Chinese texts that have emerged with international exchange are often found to contain a series of errors that need to be corrected. Chinese maritime exhibitions' bilingual promotional materials have been proven to contain shortcomings in the use of certain words and phrases. These deficiencies could have a somewhat negative influence on international business exchange and intercultural communication; thus improvement is necessary. In reaching this conclusion, this paper has analyzed the deficiencies of selected Chinese maritime-related exhibition bilingual promotional materials from 2018 to 2020 in terms of the following: redundancy; the use of Chinglish; the misuse of certain translation strategies; the abuse of CAT technology; the mismanagement of intercultural conflict. The corrections of each shortcoming have also been proven to be feasible and a series of pathways for overall improvement have been expounded.

In the context of globalization, Chinese translators and language learners need to see the development of the English language and culture in the world as a dynamic process rather than a static one. Based on this, Chinese translators and learners need to constantly advance their English language skills and cultural knowledge of English in the world, while striving to improve their intercultural communication competence and develop global citizenship. Only in these ways can China English texts in Chinese maritime exhibitions truly gain credibility, and thus the communication, as well as cooperation, between China and the rest of the world can proceed smoothly.

\section{References}

[1] A plain English handbook: How to create clear SEC disclosure documents. (1998). Washington, DC (450 5th St., N.W., Washington 20549): The Office of Investor Education and Assistance, U.S. Securities and Exchange Commission.

[2] Anderson, K. T., \& Holloway, J. (2018). Discourse analysis as theory, method, and epistemology in studies of education policy. Journal of Education Policy, 35(2), 188-221. https://doi.org/10.1080/02680939.2018.1552992

[3] Allan, K., \& Burridge, K. (2009). Forbidden words: Taboo and the censoring of language. Cambridge: Cambridge University Press.

[4] Baker, M. (2000). In Other Words: A Coursebook on Translation. London: Foreign Language Teaching and Research Press, Routledge. 
10 Ma, et al.: English in Bilingual Promotional Material of Chinese Maritime-related Exhibition Publicity: A discourse Analysis Study

[5] Bi, J. W. (2009). Kuawenhua jiaoji yu dier yuyan jiaoxue [Intercultural communication and second language teaching]. Beijing: Beijing Language and Cultural University Press.

[6] Butler, S. (1997). Corpus of English in Southeast Asia: Implications for a regional dictionary. In S. Bautista (Ed.), English is an Asian language: The Philippine context (pp. 103-124). NSW: Macquarie Dictionary.

[7] Bao, H. N. (1999). Wenhua yujing yu yuyan fanyi [Cultural context and language translation]. Beijing: China Translation \& Publishing Corporation.

[8] Chen, X. (1999). A Guide to English-Chinese Translation of Stylistic Varieties. Beijing: Peking University Press.

[9] Carciunescu, O., Gerding-Salas, Constanza., \& Susan-Stringer, O’ Keeffe. (2004).

[10] Machine Translation and Computer-assisted Translation: A New Way of Translating? Translation Journal, $8(3)$.

[11] Du, R. Q., \& Jiang, Y. J. (2001). Jin ershi nian 'Zhongguo Yingyu' yanjiu shuping [An overview of studies of 'China English' in the last two decades]. Waiyu Jiaoxue yu Yanjiu [Foreign languages teaching and research], 33(1), 37-41.

[12] Gowers, E. (2014). The complete plain words. Boston: David R. Godine.

[13] Giddens, A. (1990). The Consequences of Modernity. Cambridge: Polity Press.

[14] Garbl's Plain Language Resources. (n.d.). Retrieved from

[15] https://members.home.net.garbl/writing/plaineng.htm

[16] Gee, J. P. (2014). An introduction to discourse analysis: Theory and Method. Routledge.

[17] Hu, Z. L. (2019). Linguistics: A Course Book. (5 ${ }^{\text {th }}$ ed.). Beijing: Peking University Press.

[18] Hu, X. Q. (2005). China English, at home and in the world. English Today, 21(3), 27-38. doi: $10.1017 / \mathrm{s} 026607840500307 \mathrm{x}$

[19] Halliday, A., Hyde, M. \& Kullman, J. (2004). Intercultural communication: An advanced resource book. London: Routledge.

[20] House, J. (2008). Using translation to improve pragmatic competence. In E. A. Soler \& A. Martínez-Flor (Eds.), Investigating pragmatics in foreign language learning, teaching and testing (pp. 135-152). Bristol, UK: Multilingual Matters.

[21] Jenkins, J. (2014). English as a Lingua Franca in the International University. Routledge.

[22] Jorgensen, M., \& Phillips, L. (2011). Discourse analysis as theory and Method. Sage Publications.

[23] Johnstone, B. (2011). Discourse analysis. Blackwell.

[24] Kirkpatrick, A., \& Xu, Z. C. (2002). Chinese pragmatic norms and 'China English'. World Englishes, 21(2), 269-279. doi:10.1111/1467-971x.00247

[25] Li, C. S. (2012). Using Short Sentences. In: Fan, X. Z., Wang, X. M. (Eds.), Theory and Practice of NonLiterary Translation (pp. 76-77). Beijing: China Translation \& Publishing House.

[26] Li, C. S., \& Chen, D. Z. (2014). Lianheguo Guoji Fanyi Jiaocheng [A course in document translation for the United Nations]. Beijing: China Translation \& Publishing House.

[27] Liang, L. Q., \& Guo, S. H. (2020). Shehai yingyu fanyi wenti ji duice yanjiu [On the Translation Strategies of the Marine Exhibitions and Enterprises Based on Practical Experience]. Jiangxi Dianli Zhiye Jishu Xиeyuan Xиebao [Journal of Jiangxi Vocational and Technical College of Electricity], 33(7), 122-124.

[28] Liang, L., \& Ma, J. (2020). The revelation and correction of translated-text redundancy: Based on translation experience of major Chinese maritime exhibitions. Proceedings of the 2nd International Conference on Literature, Art and Human Development (ICLAHD 2020). https://doi.org/10.2991/assehr.k.201215.525

[29] Lian, S, N. (2010). Contrastive studies of English and Chinese. Beijing: Higher Education Press.

[30] Mcarthur, T. (2004). Is it world or international or global English, and does it matter?

[31] English Today, 20(3), 3-15. doi:10.1017/s0266078404003025

[32] Munday, J. (2008). Introducing translation studies: Theories and applications. London: Routledge.

[33] Mills, S. (1997). Discourse. London: Routledge.

[34] Newmark, P. (2004). Non-literary in the Light of Literary Translation. Journal of

[35] Specialised Translation, 1,8-13.

[36] O'Hagan, M. (2020). The Routledge Handbook of Translation and Technology. London: Routledge, Taylor \& Francis Group. 
[37] Pinkham, J. (2000). The Translator's Guide to Chinglish. Shanghai: Foreign Language Teaching and Research Press.

[38] Readability. (n.d.). Retrieved from https://www.clearlanguagegroup.com/readability/

[39] Sun, Y. Z. (2016). Waiyu jiaoyu yu kuawenhua nengli peiyang [Foreign Language Education and Intercultural Competence Cultivation]. Zhongguo Waiyu [Foreign Languages in China], 3, 16-22.

[40] Song, G. (2019). Conflicts and complexities: A study of Hong Kong's bilingual street signs from functional perspective on translation. Journal of Multilingual and Multicultural Development, 41(10), 886-898. https://doi.org/10.1080/01434632.2019.1663860

[41] Xu, J. P. (2018). Yinghan huyi shijian yu jiqiao [A Practical Course of E-C\& C-E Translation]. Beijing: Tsinghua University Press.

[42] Yang, Z. J. (2002). On Language and Linguistics. Journal of Foreign Languages, 1, 53-61.

[43] Yao, Y. B. (2015). "Haiyang" yici de yingyu biaoshu ji fanyi: jiyu lianheguo haiyangfa zhongyingwen banben de pingxing yanjiu [English expression of "haiyang (海洋)" and its translation: A parallel research on the Chinese Version of The Law of the Sea of the United Nations]. Zhejiang Haiyang Xueyuan Xuebao [Journal of Zhejiang Ocean University], 32(5), 77-81. 